\title{
Cine-Poema: a poesia de Sophia de Mello Breyner Andresen no filme de João César Monteiro
}

\section{Film-Poetry: The poetry of Sophia de Mello Breyner Andresen in the film by João César Monteiro}

Ana Catarina Pereira

Universidade da Beira Interior / LabCom.IFP (UBI), Covilhã / Portugal anacatarinapereira4@gmail.com

Resumo: "O poeta é levado a buscar a justiça." As palavras de Sophia de Mello Breyner, pronunciadas no documentário com que João César Monteiro inicia a sua filmografia, revelam a responsabilidade social com que ambos os artistas - cineasta e poetisa - encararam o percurso e posições públicas assumidas, ainda que em estilos claramente distintos. Sophia, filme que ocupa um lugar de destaque no Novo Cinema Português e que vem dar nome aos Prémios da Academia Portuguesa de Cinema, é a obra em análise no presente artigo. Reflectindo sobre o diálogo estabelecido entre os dois lados da câmara e a assumida vontade do realizador em buscar uma essência do Cinema, tentaremos identificar o modo como o espaço é filmado, na sua relação com a personagem e com o tipo de documentário resultante.

Palavras-chave: Sophia, Hans Gumbrecht, presença, espaço.

Abstract: "The poet is brought to seek justice." The words of Sophia de Mello Breyner, pronounced in the documentary with which João César Monteiro begins his filmography, reveal the social responsibility with which both artists - the filmmaker and the poet - faced the course and assumed public positions, even though in distinctly different styles. Sophia, a film that occupies a prominent place in the New Portuguese Cinema and that is now used by the Prizes of the Portuguese Film 
Academy, is the work in analysis in the present article. Reflecting on the dialogue established between the two sides of the camera and the director's willingness to pursue an essence of cinema, we will try to identify the way space is filmed, its relationship to the character and the type of documentary that comes up.

Keywords: Sophia, Hans Gumbrecht, presence, space.

Data de submissão: 9 de agosto de 2018

Data de aprovação: 10 de agosto de 2018

O primeiro filme de João César Monteiro (1969) assume uma posição singular na obra do cineasta. Formando parte, juntamente com Manoel de Oliveira e Pedro Costa, do tríptico de realizadores canónicos da História do Cinema Português, Monteiro ostenta também o título do mais polémico e incompreendido. Declarações como "O público português que se lixe" (passando-se o eufemismo), bem como o original despreendimento de uma Branca de neve (2000) projectada a negro, fizeram dele, sobretudo nos últimos anos de vida, uma figura sui generis no panorama das produções cinematográficas lusitanas. E não só.

Entre outras, as controvérsias assinaladas foram alimentando arquétipos, ao mesmo tempo que distanciaram incontáveis espectadores/ as de uma obra que, não obstante, pode ser vista como um curioso caso de estudo e reflexão sobre a sociedade do pós- 25 de Abril. A caricatura de resquícios de um Portugal salazarista elaborada em Recordações da casa amarela (1989) e n'A comédia de Deus (1995), nos cenários da pensão da Dona Violeta e n'O paraíso do gelado, constituem dois exemplos dessa mesma reflexividade. Mas apesar da progressiva viragem para a ficção, o percurso de João César Monteiro (1939-2003) inicia-se com o documentário que aqui nos propomos analisar.

A partir de Sophia, auspiciava-se um caminho essencialmente poético e menos controverso. Depois da dedicatória preambular à memória de Dreyer, o realizador introduz a própria voz nas primeiras imagens, apresentando a reduzida equipa com quem trabalhou: filme de João César Santos (só na obra seguinte assina pelo sobrenome com que 
viria a ser reconhecido); Emílio Pinto, assistente operador; Jorge Silva Melo, assistente de realização; Alexandre Gonçalves, sonoplastia; Abel Escoto, fotografia; Ricardo Malheiro, produção.

Mais tarde, na revista $O$ Tempo e o Modo, sintetizaria os seus propósitos:

No que ao meu filme diz respeito, suponho que, antes de mais, ele é a prova, para quem a quiser entender, que a poesia não é filmável e não adianta persegui-la. O que é filmável é sempre outra coisa que pode ou não ter uma qualidade poética. O meu filme é a constatação dessa impossibilidade, e essa intransigente vergonha torna-o, segundo creio, poético, malgré-lui. Creio também, e acho espantoso que a crítica não tenha dado por isso (o que, aliás, só reforça uma impressão velha sobre a infinita ignorância da dita) que muito mais do que um filme sobre a Sophia que, para mim, só de um modo aleatório é parte dele, o meu filme é um filme sobre o cinema e a matéria nele. (SANTOS, 1969, p. 405)

Discordando da breve apresentação, consideramos antes que Sophia exibe um diálogo nem sempre fácil entre dois autores: o que se situa por detrás e a que está à frente da câmara. Ao sabermos, desde Platão, que a arte nasce da experiência e do solipsismo de quem a produz, buscando a amplitude da vida humana e de receptores com novas inquietudes, olhamos o filme como o encontro de dois seres com personalidades públicas distintas, que se definem na comum necessidade de instigar outros artistas e uma sociedade amorfa. Sublinhe-se aqui o contexto político da obra (concluída em 1969 e estreada comercialmente em 1972, ${ }^{1}$ no período do Estado Novo), não apenas pela poesia que palavras e imagens espoletam, mas também pelo subtexto disruptivo, criado tanto pelo realizador quanto pela poetisa - que, a propósito, detestava a designação, preterindo-a a um sem-género "poeta". Assinalando a responsabilidade social de todos os criadores artísticos, é Sophia quem assume: "o poeta é levado a buscar a justiça".

\footnotetext{
${ }^{1} \mathrm{O}$ filme seria, mais tarde, editado em DVD pela Madragoa Filmes, juntamente com outras três curtas-metragens de João César Monteiro. Encontra-se disponível, na íntegra, no youtube em: $<$ https://www.youtube.com/watch?v=VDilav1 fgzo\&t=343s $>$.
} 


\section{Do milagre das coisas que eram minhas}

Da citação acima relembrada, detenhamo-nos na autoproposta de João César Monteiro que, de forma ambiciosa e desde o primeiro filme, pretende encontrar uma essência do Cinema, distanciando-se de outras artes. À semelhança de Sophia, nos seus poemas, o realizador centrou-se na sacralidade do quotidiano, descobrindo Deus (ou uma essência) nos detalhes que compõem a vida. A poesia de Sophia e as imagens de Monteiro buscam assim inspiração em fontes idênticas, no concerto de comuns fascínios e inesperados interesses. No entanto, se na vida e obra da poetisa, a profunda religiosidade é reconhecível, as declarações e filmes do realizador poderiam ser apresentados como a antítese, ou a denúncia de uma aversão ao catolicismo enraizado na sociedade portuguesa, não se lhe havendo notado qualquer outro tipo de manifestação espiritual. De um lado, a leveza, a melancolia e o romantismo do clássico. Do outro, a ironia, a necessidade de palco, a contestação do instituído. Do paradoxo nasce o belo, num eco das palavras de Mestre Eckhart: "Apreende Deus em todas as coisas, pois Deus está em todas as coisas. Cada criatura está cheia de Deus e é um livro sobre Deus"2 (ECKHART em ROBERTS; AMIDON, 2009, p. 251).

Em filmes posteriores, nos desmantelamentos ficcionais da religião, Monteiro assume a ironia e o sarcasmo como motivos e recursos dominantes. No início do percurso, uma certa deferência e interesse manifestados pelo outro potenciam-lhe, malgré lui, a desejada descoberta da essência do cinema [e da vida, num modo pleonástico de o (d)escrevermos]. A essência da poesia, por sua vez, pressente-se na desmistificação da mulher que recita e na acentuação do seu lado político e provocador. Ao longo de escassos 17 minutos, redescobre-se que a vida da poetisa era a sua obra, espelhada como um reflexo, e reitera-se a descrença em biografias, enquanto vidas contadas pelos outros. Imagens em movimento que nascem da generosa capacidade de observação das coisas, dos instantes em frente ao mar, ou dos que ali não passara e viria buscar depois de morrer.

\footnotetext{
2 Tradução da autora. No original: "Apprehend God in all things, for God is in all things. Every single creature is full of God and is a book about God." Poema de Eckhart publicado na Colectânea Earth Prayers, organizada por Roberts e Amidon.
} 
Quando João César Monteiro lhe invade o espaço, para o filmar, busca esses traços identitários. Acede e revela o artifício perante a câmara, menos por saber que a encenação sublinha a importância de determinados valores e ícones da poetisa, do que por se dar conta de que o cinema, enquanto verdade, comporta a obrigação da desmistificação. Ao registar as imagens, imiscui-se e imiscui-nos naqueles lugares. Ao reconstruírem a casa, a mesa, o caderno, a janela, o sofá, a praia e as ruínas, Sophia e o realizador dão-se a conhecer, identificam o modo como ela escreve/ vive e o modo como ele filma/permanece.

Um dos poemas não directamente citados no documentário lê-se nas entrelinhas das imagens, como uma presença constante na mente do realizador:

Casa branca em frente ao mar enorme,

Com o teu jardim de areia e flores marinhas

E o teu silêncio intacto em que dorme

O milagre das coisas que eram minhas.

A ti eu voltarei após o incerto

Calor de tantos gestos recebidos

Passados os tumultos e o deserto

Beijados os fantasmas, percorridos

Os murmúrios da terra indefinida.

Em ti renascerei num mundo meu

E a redenção virá nas tuas linhas

Onde nenhuma coisa se perdeu

Do milagre das coisas que eram minhas

(ANDRESEN, 2015, p. 78)

Ao contrário do que Monteiro afirma, a essência do seu cinema nasce assim de uma arte impura. A mesma que, na terminologia baziniana, alude à permanente relação criativa entre cinema e literatura. As declamações de Sophia (incluindo aquelas em que o próprio filho não reconhece a voz da mãe) assumem um carácter performativo, revelador da acção política e da responsabilidade social que foi assumindo ao longo da vida. As palavras enunciadas correspondem a actos perlocutórios inscritos em cada plano cinematográfico, sustentando-se a visão de John 
Langshaw Austin: "Eu faço coisas, ao dizer coisas"3 (1986, p. 121). No mesmo sentido, a poetisa proclama:

Quem procura uma relação justa com a pedra, com a árvore, com o rio, é necessariamente levado, pelo espírito de verdade que o anima, a procurar uma relação justa com o Homem. Aquele que vê o espantoso esplendor do mundo é logicamente levado a ver o espantoso sofrimento do mundo. Aquele que vê o fenómeno quer ver todo o fenómeno. É apenas uma questão de atenção, de sequência e de rigor. E é por isso que a poesia é uma moral. Eé por isso que o poeta é levado a buscar a justiça, pela própria natureza da sua poesia. Como Antígona, a poesia do nosso tempo diz: eu sou aquela que não aprendeu a ceder aos desastres. Mesmo que fale somente de pedras ou de brisas, a obra do artista vem sempre dizer-nos isto: que não somos apenas animais acossados na luta pela sobrevivência, mas que somos, por direito natural, herdeiros da liberdade e da dignidade do ser (minuto 5:50 do filme).

No discurso proferido, ${ }^{4}$ Sophia de Mello Breyner assume o fascínio, o interesse e, em alguns momentos, a aversão ao real, enquanto palco das constantes manifestações do mundo: justiça e injustiça, belo e monstruoso, generosidade e mesquinhez. Dotados de uma capacidade de observação e sensibilidade particulares relativas às estruturas dicotómicas, os artistas deverão educar o olhar dos seus públicos, insurgindo-se, provocando o questionamento e, por essa via, libertando. A arte pode assim originar novas perspectivas sobre um futuro que se pretende mais igualitário, num incentivo à redefinição de motivos sociais e políticos.

\footnotetext{
${ }^{3}$ Tradução da autora. No original: "I do things, in saying something."

${ }^{4} \mathrm{O}$ discurso recupera as palavras ditas por Sophia de Mello Breyner, aquando da entrega do Grande Prémio de Poesia, atribuído pela Sociedade Portuguesa de Escritores. O texto, mais extenso, seria publicado como posfácio da segunda edição do Livro Sexto (1964), e com a designação de Arte Poética III nas edições antológicas subsequentes.
} 


\section{Um quarto em frente do mar}

IMAGENS 1 e 2: Fotogramas do documentário Sophia (João César Monteiro, 1969), nos quais o realizador contrapõe planos fechados sobre o rosto da poetisa a planos abertos, de retratos de família, na casa e na praia, centrando-se na interacção das personagens / dos intervenientes com o espaço.
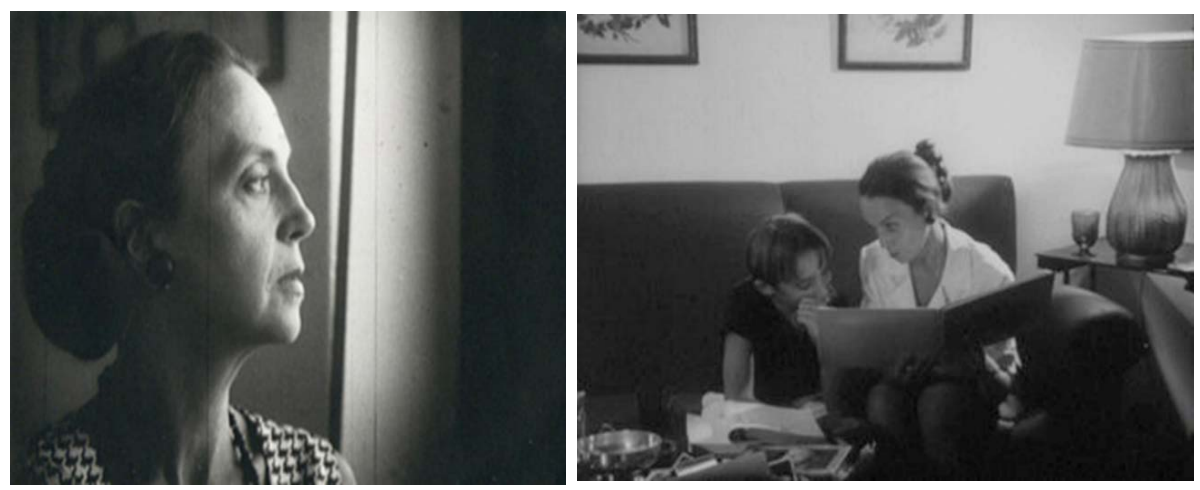

Em termos estéticos, a relação espacial entre Sophia de Mello Breyner e a câmara é ditada pela casa e pelo posicionamento dos objectos. Os escassos, mas densos, grandes-planos da imagem afecção deleuziana ${ }^{5}$ são pontos finais de João César Monteiro, que ditam a conclusão de uma acção ou discurso.

É do espaço onde Sophia e a família se movem, exibidos em planos mais abertos, que surgem as personagens. A vivenda junto ao mar participa/é uma extensão da poesia que, por sua vez, é a própria existência daquela que declama: "Se eu fizer um balanço sobre o que tem sido a minha vida, no fundo, o balanço que eu faço é exactamente o

\footnotetext{
${ }^{5}$ Segundo Gilles Deleuze, "O grande plano faz do rosto o puro material do afecto, a sua 'hilé'. Daí essas estranhas núpcias cinematográficas em que a actriz cede o rosto e a capacidade material das suas partes e o realizador inventa o afecto ou a forma do exprimível que os utilizam e os moldam" (DELEUZE, 2016, p. 161). Fora das coordenadas espácio-temporais, o grande-plano corresponde à expressão de um estado, ao afecto puro. E o autor acrescenta: "é como que o exprimido do estado de coisas, mas esse exprimido não remete para o estado de coisas, remete só para os rostos que o exprimem e que, compondo-se ou separando-se, lhe dão uma matéria própria movente" (DELEUZE, 2016, p. 165).
} 
mesmo balanço que fiz, há muitos anos, quando escrevi o Coral, que é isto: Creio na nudez da minha vida" (minuto 7:45 do filme).

Por outro lado, da relação da família com a habitação - visível tanto nos testemunhos dos filhos que, sentados no sofá, relembram episódios da infância e juventude, como nos planos individuais da poetisa, nos quais irrompem as mesmas crianças, indiferentes ao filme que ali se documenta - sobressai uma naturalidade infantil, inversa à seriedade e postura enfática de Sophia. Neste ponto, recordamos a questão analítica existencial de Martin Heidegger (2001), que passa precisamente pelo ser-aí, pelo ser-no-mundo, ou pelo modo como o habitamos. Para o filósofo, existem distinções claras entre "estar numa casa" e, de facto, "habitá-la", o que Sophia parece reiterar nos seus versos:

Há sempre um deus fantástico nas casas

Em que eu vivo, e em volta dos meus passos

Eu sinto os grandes anjos cujas asas

Contêm todo o vento dos espaços

(ANDRESEN, 2015, p. 187)

$\mathrm{Na}$ língua alemã, as formas verbais "ich bin / eu sou”, " $d u$ bist / tu és" podem também traduzir-se por "eu habito", "tu habitas", estabelecendo-se paralelismos entre as duas acções. Por sua vez, para Heidegger, a existência humana - a vida a acontecer, a ser-no-mundo - corresponde essencialmente ao acto de habitar. Não sentir a pertença a um determinado lugar, ainda que transitório, causa desconforto e intranquilidade. Le Corbusier acentuaria estas consequências ao afirmar: "Tomar posse do espaço é o primeiro gesto dos seres vivos, homens e animais, plantas e nuvens, manifestação fundamental do equilíbrio e da duração. A primeira evidência da existência é a ocupação do espaço" (LE CORBUSIER, 1945). ${ }^{6}$ Nesse sentido, a geografia de Sophia seria delimitada nos seus poemas e reconstruída no filme de Monteiro.

Seguindo a perspectiva heideggeriana, Hans Gumbrecht lançaria um apelo ao maior contacto e à fascinação pelo que existe ou se manifesta no quotidiano. Opondo-se ao que considera ser o domínio injustificado da Hermenêutica (enquanto interpretação e procura de

\footnotetext{
${ }^{6}$ Tradução da autora. No original: "Prendre possession de l'espace est le geste premier des vivants, des hommes et des bêtes, des plantes et des nuages, manifestation fondamentale d'équilibre et de durée. La preuve première d'existence, c'est d'occuper l'espace."
} 
sentido) nas Ciências Sociais e Humanas, o historiador e crítico da literatura entende que a herança cartesiana da Modernidade conduziu a uma espiritualidade metafísica. Na sua opinião, os seres humanos não são agentes transformadores, situados à parte do mundo, mas organismos que podem voltar a contactar com tudo de um modo mais puro: "Se atribuirmos um sentido a alguma coisa presente, isto é, se formarmos uma ideia do que essa coisa pode ser em relação a nós mesmos, parece que atenuamos inevitavelmente o impacto dessa coisa sobre o nosso corpo e os nossos sentidos" (GUMBRECHT, 2010, p. 14).

Numa cultura de sentido, relembra Gumbrecht, a autorreferência humana predominante é o pensamento ou a consciência, enquanto numa cultura de presença é o corpo que assume a dominação. Nesta última, o conhecimento é revelado (e não tanto descoberto ou interpretado) em epifanias ou "momentos de intensidade", que ditam a efemeridade da própria revelação. Esses momentos - assim designados por preterência do conceito "experiência estética" - adquirem o estatuto de evento, uma vez que o tempo e a intensidade com que irão decorrer são variáveis desconhecidas.

Poderá assim viver-se tão mais intensamente quanto mais poeticamente se conseguir experienciar o fascínio da realidade, o que em tudo se relaciona com a crença de Sophia: "Aquilo que eu procurei foi esse espírito de nudez. Foi pôr-se em frente de cada coisa como se ela nunca tivesse sido vista, e começar a olhar desde o princípio, como se fosse o primeiro dia do mundo" (minuto 8:04 do filme). Por detrás da câmara, João César Monteiro observou o espaço como parte integrante do ser, reactivando a dimensão corpórea e espacial da existência. A declamação da poetisa seria consentânea:

A coisa mais antiga de que me lembro é de um quarto em frente do mar, dentro do qual estava, poisada em cima de uma mesa, uma maçã enorme e vermelha. Do brilho do mar e do vermelho da maçã erguia-se uma felicidade irrecusável, nua e inteira. Não era nada de fantástico, não era nada de imaginário: era a própria presença do real que eu descobria. Mais tarde, a obra de outros artistas veio confirmar a objectividade do meu próprio olhar. Em Homero reconheci essa felicidade nua e inteira, esse esplendor da presença das coisas. E também a reconheci, intensa, atenta e acesa, na pintura de Amadeo de Souza-Cardoso. Dizer que a obra de arte 
faz parte da cultura é uma coisa um pouco escolar e artificial. A obra de arte faz parte do real e é destino, realização, salvação e vida (minuto 4:41 do filme). ${ }^{7}$

Em concordância teórica com as opções estéticas de Monteiro ao filmar a casa de Sophia e a sua relação com os objectos, Edward T. Hall afirma que o espaço é um meio de comunicação, organizado de forma diferente em cada cultura. No entender do antropólogo, "visualizamos a relação entre lugares que conhecemos por experiência" (HALL, 1994, p. 190), existindo uma tendência natural para a personalização daquele, bem como para o estabelecimento de pontos de referência. Le Corbusier entenderia também que: "A chave da emoção estética é uma função espacial" (1945). ${ }^{8}$ Nesse caso, a proposta documental do realizador sugere idênticas necessidades de reconhecimento e de intertextualidades. Assim, tal como João César Monteiro parece recitar "Casa branca" enquanto filma, também quem assiste às imagens captadas na praia e nas formações rochosas tem novas possibilidades de relacionamento com as palavras da poetisa no Livro sexto:

O esplendor poisava solene sobre o mar. E - entre as duas pedras erguidas numa relação tão justa que é talvez ali o lugar da Balança onde o equilíbrio do homem com as coisas é medido - quase me cega a perfeição como um sol olhado de frente. Mas logo as águas verdes em sua transparência me diluem e eu mergulho tocando o silêncio azul e rápido dos peixes. Porém a beleza não é só solene mas também inumerável. De forma em forma vejo o mundo nascer e ser criado. Um grande rascasso vermelho passa em frente de mim que nunca antes o imaginara. Limpa, a luz recorta promontórios e rochedos. É tudo igual a um sonho extremamente lúcido e acordado. Sem dúvida um novo mundo nos pede novas palavras, porém é tão grande o silêncio e tão clara a transparência que eu muda encosto a minha cara na superfície das águas lisas como um chão. (ANDRESEN, 2015, p. 445)

Novamente, a importância de olhar o que se encontra em presença, contrariando a separação. A solenidade que advém da luz espontânea,

\footnotetext{
${ }^{7}$ No filme, Sophia de Mello Breyner lia o Livro sexto, pelo qual havia recebido, em 1964, o Grande Prémio de Poesia da Sociedade Portuguesa de Escritores.

${ }^{8}$ Tradução da autora. No original: "La clef de l'émotion esthétique est une fonction spatiale."
} 
diante de quem se dá conta, e a importância do silêncio como reacção à epifania, ao "momento de intensidade".

Na esteira do pensamento de Elliot Gaines, o espaço corresponde ao enquadramento fornecido para a percepção inicial do mundo de Sophia: "O espaço é o papel no qual escrevo as minhas palavras, o silêncio que faz com que os sons musicais adquiram significado em relação a outros sons, e a distância entre os objetos cujos significados são dependentes de relações espaciais"9 (GAINES, 2006, p. 173). No seguimento de Aristóteles, Kant, Hegel e Peirce, o espaço corresponde a uma categoria conceptual percepcionada em relação a outros temas (as palavras e os gestos da poetisa e da restante família), ao invés de individualmente. Apesar de desempenhar uma função menos óbvia na construção de significado, quando comparado com outras formas mais activas de comunicação, a sua importância enquanto signo é reiterada por diferentes autores. Entre eles, Martin Esslin sustenta:

O espaço da performance - quer se trate do palco de um teatro, do ecrã de um televisor ou de uma sala de cinema ... transforma o quotidiano mais comum e as trivialidades da existência em portadores de significado. Pendure uma moldura vazia, sem qualquer imagem, na parede $-\mathrm{e}$, de repente, a textura da parede atribui significado a algo dentro dela. ${ }^{10}$ (ESSLIN, 1987, p. 38)

Deste modo, pretendendo distanciar-se das outras artes, Monteiro consagraria o Cinema como um dos meios de comunicação mais próximos da Arquitectura, na reconstrução e reprodução exímia do espaço, numa mimetização dificilmente alcançável pela Pintura ou pela Escultura, pela Literatura ou pela Poesia.

\footnotetext{
${ }^{9}$ Tradução da autora. No original: "Space is the paper on which I write my words, the silence that makes musical sounds have meaning in relation to other sounds, and the distance between objects whose meanings are dependent on spatial relations."

${ }^{10}$ Tradução da autora. No original: "The performance space-whether it is the stage of the live theatre or the cinema and television screen ... transforms the most ordinary and everyday trivial of existence into carriers of significance. Hang an empty picture frame on the wall - and suddenly the texture of the wall makes anything within it significant."
} 


\section{A beleza não é só solene mas também inumerável}

O primeiro plano do filme - com Sophia à janela, em contraluz, escrevendo - terá sido o desejado por ambos, realizador e poetisa, na constituição de um retrato formal. Segue-se uma sequência de imagens na praia: barco, mergulhos, sorrisos, rochas e o retrato de família igualmente desejado. À noite, Sophia lê $A$ menina do mar para um dos filhos que, contornando a linearidade do argumento, entende que aquela "não parece a voz da mãe". A desconstrução pela espontaneidade favorece a identificação, tornando-se um dos traços autorais de João César Monteiro.

De forma embrionária, o realizador começa a afirmar-se na escassa edição, na ironia, no respeito pela duração natural do plano cinematográfico e na contestação das dúbias fronteiras entre ficção e documentário. "Isto é cinema" é a mensagem que transparece, deixando margem para debates ulteriores. Ainda que Sophia seja formalmente apresentado como documentário, a linguagem poética utilizada de ambas as partes nem sempre direcciona quem assiste numa única possibilidade de sentido. Por essa razão, importa que nos centremos também na categorização do filme, segundo as concepções propostas por Bill Nichols (2010). Pelo hibridismo e pela contestação de fronteiras acima mencionadas, consideramos que Sophia corresponde fundamentalmente ao modo reflexivo, o mais questionador da forma como o documentário actua e intervém na realidade. Ao negar a premissa da fidelidade da câmara ao real, este tipo de filmes estimula a reflexão em torno dos conceitos de veracidade e espontaneidade dos/as entrevistados/as diante do dispositivo.

Exibindo as cenas familiares que, provavelmente, Sophia desejaria ver cortadas, Monteiro provoca e assume não ter dirigido um filme sobre a poetisa, mas antes sobre a essência do cinema. Por outro lado, o facto de não existir uma voz-off que delimite a biografia da figura central ultrapassa também os objectivos de um documentário meramente expositivo. João César Monteiro entra na casa de família, filma uma existência que vai a meio e que prosseguirá somando episódios caricatos, irrompendo a seriedade dos poemas. Aquelas crianças já brincavam quando terão sido avisadas da chegada de uma equipa de filmagem. Ao invés de reagirem com a sobriedade de "meninos de coro", impuseram-se pela excentricidade veraneante que se coaduna com uma casa de praia. Não existe, portanto, prólogo ou epílogo, mas uma sucessão de acontecimentos 
e palavras: um fragmento de dezassete minutos que potencia a revelação de uma vida.

Os fundamentos do documentário e a sua aproximação à verdade podem assim ser questionados por quem assiste. Sobre esse aspecto, Jacques Rancière viria sublinhar que informação e memória não são sinónimos, não correspondendo a última ao simples conjunto de lembranças de uma consciência. Se assim fosse, a própria ideia de memória colectiva seria vazia de sentido: "Uma memória é um certo conjunto, um certo arranjo de signos, de vestígios, de monumentos. $\mathrm{O}$ túmulo por excelência, a Grande Pirâmide, não guarda a memória de Queóps. É em si mesmo essa memória" (RANCIĖRE, 2014, p. 255). Tal como a casa de praia consiste, em si, no arquivo de recordações daquela família, os planos detalhados, dirigidos pelo cineasta, são a sua reconstituição.

Seguindo a exposição argumentativa, o documentário é ainda reconhecido pelo filósofo como um género de ficção, embora não propriamente em termos de falsidade ou de contar histórias opostas à realidade. A primeira acepção de fingere, relembra, não é fingir, mas sim forjar:

A ficção é a construção, por meios artísticos, de um "sistema" de acções representadas, de formas agregadas, de signos que respondem uns aos outros. Um filme "documentário" não é o oposto de um "filme de ficção", porque nos mostra imagens saídas da realidade quotidiana ou de documentos de arquivos de acontecimentos confirmados, em vez de empregar actores para interpretar uma história inventada. Não opõe o já dado do real à invenção ficcional. Simplesmente, o real não é, para ele, um efeito por produzir, mas sim um dado por compreender (RANCIÈRE, 2014, p. 257).

Para João César Monteiro, essa seria a razão (ou a essência) de fazer cinema. Sophia é uma compreensão do real e da memória de dois autores, num entrelaçar de Cinema e Literatura, Vida e Teatro. 


\section{Referências}

ANDRESEN, S. Obra poética. Porto: Assírio \& Alvim, 2015.

AUSTIN, J. L. How to do things with words. Oxford: Oxford University Press, 1986.

DELEUZE, G. A imagem-movimento. Cinema 1. Trad. Sousa Dias. Lisboa: Documenta, 2016.

ESSLIN, M. The field of drama: How the signs of drama create meaning on stage and screen. London: Melthuen London, 1987.

GAINES, E. Communication and the semiotics of space. Journal of Creative Communications, New Delhi, v. 1, n. 2, p. 173-181, 2006. DOI: https://doi.org/10.1177/097325860600100203 Disponível em: <http:// www.wright.edu/ elliot.gaines/space.pdf $>$. Acesso em: 2 jul. 2018.

GUMBRECHT, H. U. Produção de presença. Trad. Ana Isabel Soares. Rio de Janeiro: Contraponto; Editora PUC-Rio, 2010.

HALL, E. T. A linguagem silenciosa. Trad. Manuela Paraíso. Lisboa: Relógio d'Água Editores, 1994.

HEIDEGGER, M. Ensaios e conferências. Trad. Emmanuel Carneiro Leão, Gilvan Fogel e Marcia Schuback. Petrópolis: Editora Vozes, 2001.

LE CORBUSIER. L'espace indicible. L'Architecture d'Aujourd'Hui, 1945. Disponível em: $<$ http://www.philo52.com/articles.php?pg=1739>. Acesso em: 7 jul. 2018.

NICHOLS, B. Introduction to documentary. Bloomington: Indiana University Press, 2010.

RAMOS, J. L. Dicionário do Cinema Português 1962-1988. Lisboa: Editorial Caminho, 1989.

RANCIÈRE, J. A fábula cinematográfica. Trad. Luís Lima. Lisboa: Orfeu Negro, 2014.

ROBERTS, E.; AMIDON, E. (Org.). Earth prayers. San Francisco: HarperOne, 2009. 
SANTOS, J. C. Entrevista com João César Santos. O Tempo e o Modo, Lisboa, n. 69/70, p. 403-410, mar./abr. 1969. Entrevista conduzida por Denis Cintra. Disponível em: $<\mathrm{http}: / /$ casacomum.org/cc/ visualizador?pasta=09524.052\#!1>. Acesso em: 19 jul. 2018.

\section{Filmografia de João César Monteiro}

Sophia, 1969, Portugal

Recordações da casa amarela, 1989, Portugal

A comédia de Deus, 1995, Portugal

Branca de Neve, 2000, Portugal 
